\title{
Editorial
}

\section{Reputation and Reputational Risk Management}

\author{
Kai-Uwe Schanz ${ }^{1}$ \\ Converium Ltd, General Guisan-Quai 26, Zurich 8022, Switzerland. \\ E-mail: kai-uwe.schanz@converium.com
}

The Geneva Papers (2006) 31, 377-381. doi:10.1057/palgrave.gpp.2510092

This special edition of the Geneva Papers on Risk and Insurance is devoted to the management of reputation, a concept that includes both the exploitation of opportunities arising from a superior reputation and the containment of risks associated with a sudden or gradual loss of reputation. The following introductory thoughts are aimed at helping clarify a discussion that still abounds with semantics and is short of strategically and operationally relevant applications for the insurance industry - shortcomings that are authoritatively and convincingly addressed by the contributions published in this special edition.

\section{What is reputation?}

There have been a plethora of sophisticated attempts to understand the concept of "reputation". What appears to be a common thread through various studies is the understanding of reputation as a comprehensive set of enduring stakeholder perceptions, opinions and expectations.

\section{Why does reputation increasingly matter to insurers?}

Why is The Geneva Association venturing into an area where buzzwords abound, terminological stringency is hard to achieve and a quantitative approach to measurement seems to be remote? The answer is the increasing relevance of reputation as one the insurance industry's key assets, offering attractive returns when properly cultivated but also threatening considerable damage if eroded or lost. In the case of the former, the potential return from reputation can materialize as increased sales, as the ability to command a premium on market prices, as access to talent, or as a stock market valuation in excess of book value. If an insurers' reputation is sufficiently tarnished, the company may be faced with an exodus of clients, the defection of key staff and a spiralling cost of capital.

Insurers are in the business of trust. They sell contingent promises to pay, more often than not at a distant point in the future. From a policyholder's perspective, the insurer's willingness and ability to fulfill these promises cannot be assessed until a claim is made. Clearly, for financial services in general, and for insurers in particular,

\footnotetext{
${ }^{1}$ Chief Communication and Corporate Development Officer, Converium Ltd, Zurich. The author expresses his personal views.
} 
the trust of policyholders and other stakeholders is a necessary condition for conducting business. Trust capital is primarily accumulated through corporate performance that consistently meets or exceeds stakeholder expectations. Building this capital is in a company's direct sphere of influence - as opposed to public perceptions as shaped, for example, by the media.

Considering the role of reputation in insurance, it is astonishing to note the relative shortage of (academic) attempts to thoroughly analyze this phenomenon and its specific ramifications for one of the world economy's most significant industries, which constitutes more than 8 per cent of global GDP. This state of affairs could arguably be viewed as a result of the industry's long tradition of operating in relative obscurity and isolation, in a heavily regulated environment characterized by limited competition and, accordingly, stakeholder interest and scrutiny. These conditions have only recently - but radically - changed with the onslaught of competition brought about by the deregulation of rates, terms and conditions (e.g., in Europe and Japan), the liberalization of market access to foreign providers (e.g., through the single European passport and the WTO-driven dismantling of barriers to market access in the emerging insurance world of Asia and Latin America). This "competitive shock" has been compounded by recent developments such as major shifts in the risk landscape (e.g., the 9/11 terrorist attacks), the financial market turmoil in 2001-2003 and significantly increased governmental and regulatory scrutiny as from 2004.

There can be no doubt that the business environment of the insurance industry has grown considerably more volatile and less predictable. From a historical perspective, there has been a seismic shift - heightening the importance of reputation and trust as key determinants of stakeholder behavior and catapulting these notions towards the top of corporate agendas.

\section{How can reputation be managed?}

There are differing views regarding the extent to which reputation can be managed and controlled. Assuming public opinion and perception are the main drivers of corporate reputation, there is, of course, less scope for managing reputation than under the assumption that reputation is primarily the result of corporate performance in its core business.

Some experts (both practitioners and academics) tend to focus reputation management on improving corporate performance - delivering top-class insurance services to policyholders, generating attractive shareholder returns and offering an inspiring and fulfilling environment for the company's employees. More specifically, some advocates of this view look at the corporate value chain and try to find areas of optimization in order to enhance the company's reputation with its stakeholders. Examples include the launch of innovative, tailor-made insurance solutions and an acceleration of the claims settlement process. Ultimately, for this school of thought, reputation management focuses on those stakeholders that directly interact with the company.

Other experts, including many "hard-nosed" business people, place greater emphasis on stakeholder groups, which form their perceptions and beliefs through 
secondary sources (primarily the media), without necessarily having any direct interaction with the company. The proponents of this view adopt a wider range of reputation management measures such as implementing a triple-bottom-line approach, based on corporate governance and responsibility. This more comprehensive stakeholder approach focuses on influencing rather than controlling reputation.

Whichever school of thought, there is a broad agreement that effective reputation management, be it in a shaping or an influencing form, requires an appropriate balance between enhancing core business processes, engaging with stakeholders through communications and implementing suitable internal policies such as governance and compliance.

\section{Overview of this special edition}

The following pages offer nine in-depth contributions from a wide spectrum of perspectives: corporate executives, trade body leaders, rating and financial analysts, media monitoring professionals and academic scholars set out their thoughts and views on the importance of reputation and reputational risk in the insurance industry and possible ways of promoting, protecting and measuring this asset.

Ernst Csiszar and Gregory W. Heidrich (Property Casualty Insurers Association of America) explore reputational risk and its implications from an industry perspective. They highlight the corporate governance scandals of the recent years as catalysts for increasing (and potentially adverse) regulation and litigation, and offer some thoughts on the more specific link between insurers' reputation and the likelihood of burdensome new laws and regulations. The authors view information asymmetries as a main reason for the importance of reputation, with particular relevance to insurance. They consider reputation as an effective signalling device vis- $a$-vis customers, regulators and the general public. The authors finally offer three industry case studies to discuss reputation: catastrophe exposure, terrorism and underwriting criteria.

Robert G. Eccles and Matthias Vollbracht (Perception Partners and Media Tenor International Research) discuss the changing reputational risk environment for insurers by offering an empirical long-term analysis of German media coverage as well as comparative data from other European markets, the U.S. and Asia. The authors reveal that even though the financial performance of German insurers has recovered significantly in recent years, media coverage has not. Their advice to companies is to adopt a proactive stance on corporate communications to address this mismatch and to contain resulting reputational risks. To this end, they suggest insurers focus on communicating what are the value drivers of insurance, based on the "Value Reporting" framework.

Peter Forstmoser and Nikodemus Herger (Swiss Re) place reputation management in the context of corporate values, corporate governance, corporate responsibility and the "triple bottom line". They advocate the triple-bottom-line approach as a response to heightened stakeholder scrutiny of companies and the increasing unpredictability of the mass media's impact on corporate reputation. The authors stress that this approach has nothing to do with altruism, but reflects an imperative for doing 
business in today's world. Based on Swiss Re's experience, they share specific insights on the implementation of reputation management, for example, through corporate citizenship, sustainability management, corporate compliance and the company's core business of risk transfer and mitigation and its benefits to society at large.

Sophie Gaultier-Gaillard and Jean-Paul Louisot (Université Paris Sorbonne) offer a comprehensive analysis of "reputation" from a management science perspective, elaborating on relevant findings from game theory, finance theory and marketing theory. They view a company's goals and values as well as its conduct and actions as the main determinants of corporate reputation. The authors also establish a clear link between corporate governance and risk management on the one hand and reputation on the other.

Kunio Ishihara (Tokio Marine \& Nichido Fire Insurance Co.) points out that in Japan, as in other parts of the world, there is a growing public awareness of corporate responsibility. As a key industry-specific driver, he identifies the deregulation and detariffication of the Japanese insurance market, which have made corporate reputation a crucial factor in the policyholders' purchasing decision. The author stresses the decisive role of every single insurance company employee, especially client-facing agents, in shaping the reputation of Tokio Marine \& Nichido Fire Insurance Co. He also suggests that Corporate Social Responsibility is best practised based on an insurer's core business and a clear articulation of the economic and social benefits associated with it.

Stefan Schürmann (Crédit Agricole Cheuvreux) adopts the investor's angle. He refers to large catastrophe losses, regulatory and governmental investigations and pension misselling scandals as factors which have heightened the importance of reputation in the insurance industry. The author acknowledges that reputation as conveyed by management action and communication increasingly matters. However, he also reveals, based on a survey conducted among 10 major European investors in insurance stocks, that reputation is not an explicit component of investors' valuation models.

George Stansfield (AXA) defines "reputation" as a blended perception of a company's financial performance, client trust and service, corporate social responsibility, governance and disclosure as well as compliance in a broad sense. From a global financial institution's perspective, he discusses one of the great managerial challenges: finding the right balance between promoting and protecting corporate reputation. In the context of promoting reputation, he points out that any effective course of action needs to address both "harder" elements, such as a company's financial strength and technical expertise, and "softer" elements, such as corporate ethics. The author also shares AXA's specific approach towards, and experience with, managing reputation.

Gordon Stewart (Insurance Information Institute) suggests that reputation results from actions taken over time. He consequently views an organization's own behavior as the most serious threat to its reputation, rather than the media or business adversaries. The author is wary of the notion of "reputation management" as this could lead organization leaders to believe that the effects of their actions on their reputations can be managed. Ultimately, this approach could dangerously widen the gap between appearance and reality. Based on data describing the public perception of 
the U.S. insurance industry, he advocates reputable behavior supported by credible and energetic communications as the main contributors to reputation.

Michael Zboron (A.M. Best) considers reputational risk as one of the biggest threats for insurance companies. He points out that the promise to provide insurance cover is based on the trust a policyholder has in an insurer that it will be able and willing to honor its commitment. Any doubt in an insurer's commitment as a result of financial constraints, but also due to business practices, could have a significant negative impact on its business profile, one of A.M. Best's main rating components. The author views the management of reputational risk as intrinsically linked to an insurer's overall risk assessment and risk control strategy.

The distinguished set of papers compiled in this special edition will certainly stimulate debate and dialogue between the industry and its stakeholder groups. Most contributions published in this volume highlight the increasing relevance of severe reputational risks facing the insurance industry in a social, political and economic landscape which is shifting rapidly. Mounting stakeholder scrutiny and vigilance make the industry's business environment increasingly unpredictable. This should not, however, give rise to "collective depression" among insurers and reinsurers. As various authors point out, opportunities abound for the industry to promote and positively influence its reputation as a provider of services which hugely benefit society at large from peak risk mitigation enabling entrepreneurial risk-taking and innovation to comprehensive financial protection offering "peace of mind" for millions of policyholders.

The effectiveness of reputation management will ultimately determine the strategic freedom the insurance industry enjoys in shaping its future. In order to maintain and further expand its strategic freedom, the industry needs to develop and apply both state-of-the art crisis management and reputation promotion skills, based on a selfconfident articulation of its vital contribution to economic, social and technological progress. 